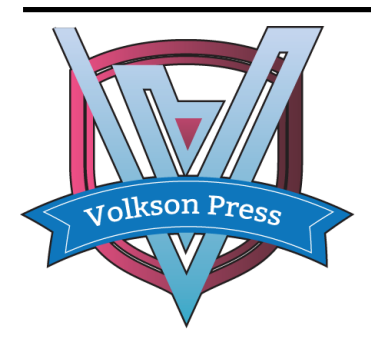

Contents List available at VOLKSON PRESS

New Materials and Intelligent Manufacturing (NMIM)

DOI : http://doi.org/10.26480/icnmim.01.2018.139.142

Journal Homepage: https://topicsonchemeng.org.my/

ISBN: 978-1-948012-12-6

\title{
DESIGN AND REALIZATION OF FULL-AUTOMATIC DOUBLE-ENDED TRIM SAW
}

\author{
Sun Mingge, Zhang Jie, Zhang Xiaodong* \\ College of Information \& Control Engineering, Jilin Institute of Chemical Technology, Chengde Street, Jilin, China. \\ *Corresponding Author Email: 746801996@qq.com
}

This is an open access article distributed under the Creative Commons Attribution License, which permits unrestricted use, distribution, and reproduction in any medium, provided the original work is properly cited

\section{ARTICLE DETAILS}

\section{Article History:}

Received 26 June 2018 Accepted 2 July 2018 Available online 1 August 2018

\section{ABSTRACT}

Conventional wood-processing machine is operated manually with deficiencies such as low working efficiency, low precision and high labor cost. Our design of full-automatic double-ended trim saw adopts the Delta PLC as controller, uses the servo motor as execution unit, utilizes the touch screen to monitor the process of wood processing, and achieves the full-automatic detection and processing of double-ended wood trimming. Through verification in practical application, our designed full-automatic double-ended trim saw effectively enhances the wood processing efficiency, reduces the production cost, and has good market prospect.

\section{KEYWORDS}

PLC, servo motor, double-ended trim saw

\section{INTRODUCTION}

Mechanization of China's wood processing industry dates from the Late Qing Dynasty and has a history of hundreds of years [1]. Conventional wood-processing machine is often operated manually, which cannot satisfy the requirements of mechanical automation and automated and intellectualization in the development of modern industry. As for the realization of automatic production for wood-processing machine, it can increase production efficiency, reduce energy consumption and labor cost, achieve energy-saving and emission-reducing objectives, as well as enhance enterprise's competitiveness [2-5]. For this purpose, in this paper we design an automatic double-ended trim saw to achieve fullautomatic detection and double-ended wood trim processing.

\section{SYSTEM SCHEME}

\subsection{System Structure}

The double-ended trim saw is applied in wood trim processing, composed by the feeding unit, the detection unit, the cutting unit and the push unit. Each unit is under centralized control of the PLC. The system function structure of our designed full-automatic doubleended trim saw is depicted in Figure 1.

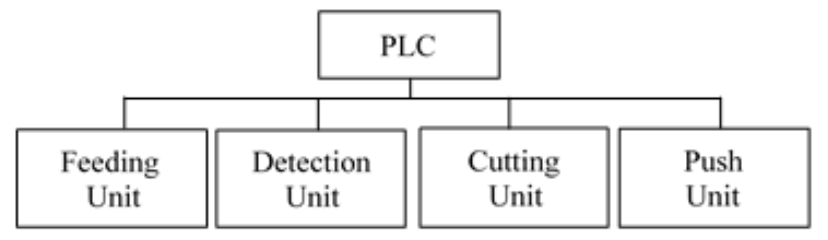

Figure 1: System Function structure of Full-automatic Double-ended Trim Saw

\subsection{Working Process}

The feeding unit of the trim saw transfers the wood which is waiting to be processed to the detection unit. Then the servo motor in the detection unit drives the laser sensor to detect the end faces of the wood.

The PLC computes the minimal distance that needs to be cut in the twoside wood head faces according to the test data from the sensor. After $\mathrm{x}$ - axis and $y$-axis coordinate transformations of the minimal cutting distance by the detection unit servo motor, the moving coordinate of the servo motor in the cutting unit can be obtained. The servo motor located in the cutting unit drives the two saw benches to move. When the saw benches move into position, the air cylinder in the push unit pushes the wood to pass through the saw bench and finishes the trimming process in two-side wood head faces with precise control. The simple structure of the fullautomatic double-ended trim saw is depicted in Figure 2.

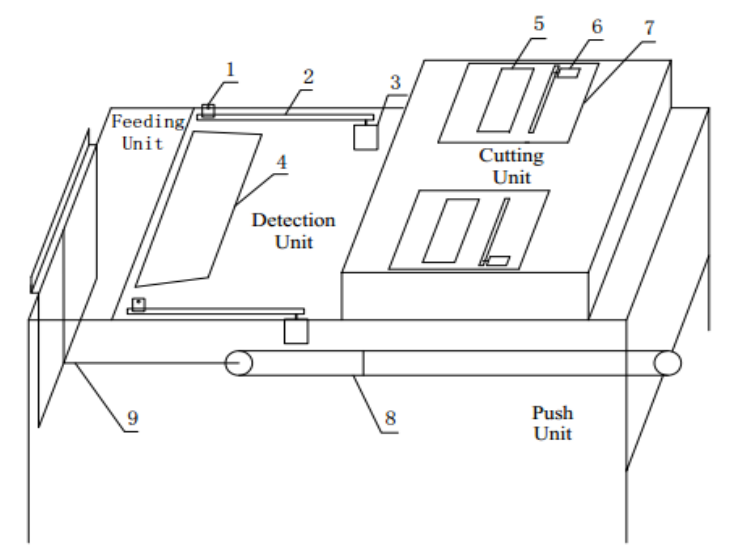

Figure 2: System Function structure of Full-automatic Double-ended Trim Saw

Notes. 1. Laser sensor, 2. Slide track, 3. Servo motor of detection unit, 4. Wood to be cut, 5. Saw-cutting main engine, 6. Servo motor of cutting unit, 7. Movable saw bench, 8. Air cylinder, 9. Push structure.

\subsection{Technical Core}

The technical core of our designed full-automatic double-ended trim saw is the data detection of the detection unit. Considering the different shape of two-side wood head faces, it is how to obtain the minimal cutting distance of the two-side wood head faces that the key to achieve precise control in the process of wood processing. 
Since wood had irregularity in two-side head faces, in this paper we compute the minimal cutting distance by the method of calculating the head face slope. For our designed trim saw, after the laser sensor of the detection unit finishes the data acquisition process, the controller calculates the derivation of the multi-group acquired data with same time interval and obtains the slope between adjacent points. Within the margin of error for measured slope, we find out as many approximate slope values as possible, from which the optimal value of the head face to be cut can be extracted.

\section{HARDWARE SCHEME}

\subsection{Sensor Design}

\subsubsection{Photoelectric Sensor \& Proximity Switch}

The photoelectric sensor is located in the feeding unit of the system and mainly used to detect whether there is wood waiting to be processed at the feeding throat. The proximity switch works as a limit switch as well as a reset switch respectively for protection and zero-resetting of the servo motor.

\subsubsection{Laser Sensor}

The laser sensor is located in the detection unit of the system and drove by servo motor. In order to detect the two-side wood head faces, the PLC controls the servo motor by pulse to move fast from the initial position to where the wood has the maximal width. Then the PLC computes and find out the minimum cutting distance of the two-side wood head faces on the basis of the measured data.

\subsection{Cutting Unit Servo Motor}

The servo motor in the cutting unit is the execution unit of the fullautomatic double-ended trim saw system. The servo motor located in the cutting unit will transform the acquired minimal cutting distance of head face in both $\mathrm{x}$-axis and $\mathrm{y}$-axis, and then drive the two saw benches to move into position precisely.

\subsection{Pneumatic Device}

The pneumatic device is part of the push unit in the system. Once the saw benches have been adjusted in place, the PLC begins to send control signal as suggested in a study and the air cylinder pushes the wood to pass through the cutting unit to finish the cutting process for the two-side wood head faces [6]. During the whole cutting process, the protective device installed at both ends of the pneumatic device will guarantee the security of the air cylinder.

\section{CONTROL SYSTEM DESIGN}

\subsection{PLC Program Design}

The PLC program designed for our trim saw automatic system not only includes the technological requirement and parameter settings of wood processing, but also includes interlocking and safety alarming functions, aiming to guarantee both personal safety and device security as well as improve the safety, stability and reliability of the whole system $[7,8]$. The control flow of the full-automatic double-ended trim saw is depicted in Figure 3.

The full-automatic double-ended trim saw control system can operate in two modes, Manual Mode and Automatic Mode. In the case of Manual Mode, the operation staff is able to separately control the start-stop of devices such as cutting motor and air cylinder by touch screen, as well as inching adjustment and fixed-point moving operation for servo motor, which is convenient for device debugging and overhauling. In the case of Automatic Mode, by pressing BUTTON START in touch screen, the trim saw will mainly adopt sequential control and finish the process of fullautomatic wood processing according to corresponding working procedures.

\subsubsection{Initialization \& Mode Selection}

After the system is powered, the PLC executes the initialization program.
The servo motors are reset to the initial position. Each technics unit is ready to work. The system keeps in suspend mode and prepares to execute the following programs. According to the production plan, the operating staff is able to select operation modes by touch screen.

\subsubsection{System Start-up}

When the control system works in Automatic Mode, the sequential loop PLC control of feeding unit, detection unit, cutting unit and push unit of the trim saw can be implemented by pressing BUTTON START in touch screen, and the full-automatic double-ended wood trimming process can be completed.

\subsubsection{Counting \& Archiving}

The counting program can not only realize the statistics of wood processing amount, but also achieve the archiving operation of wood processing amount, which is easy for the managerial staff to inquire the amount of wood processing and gather statistics.

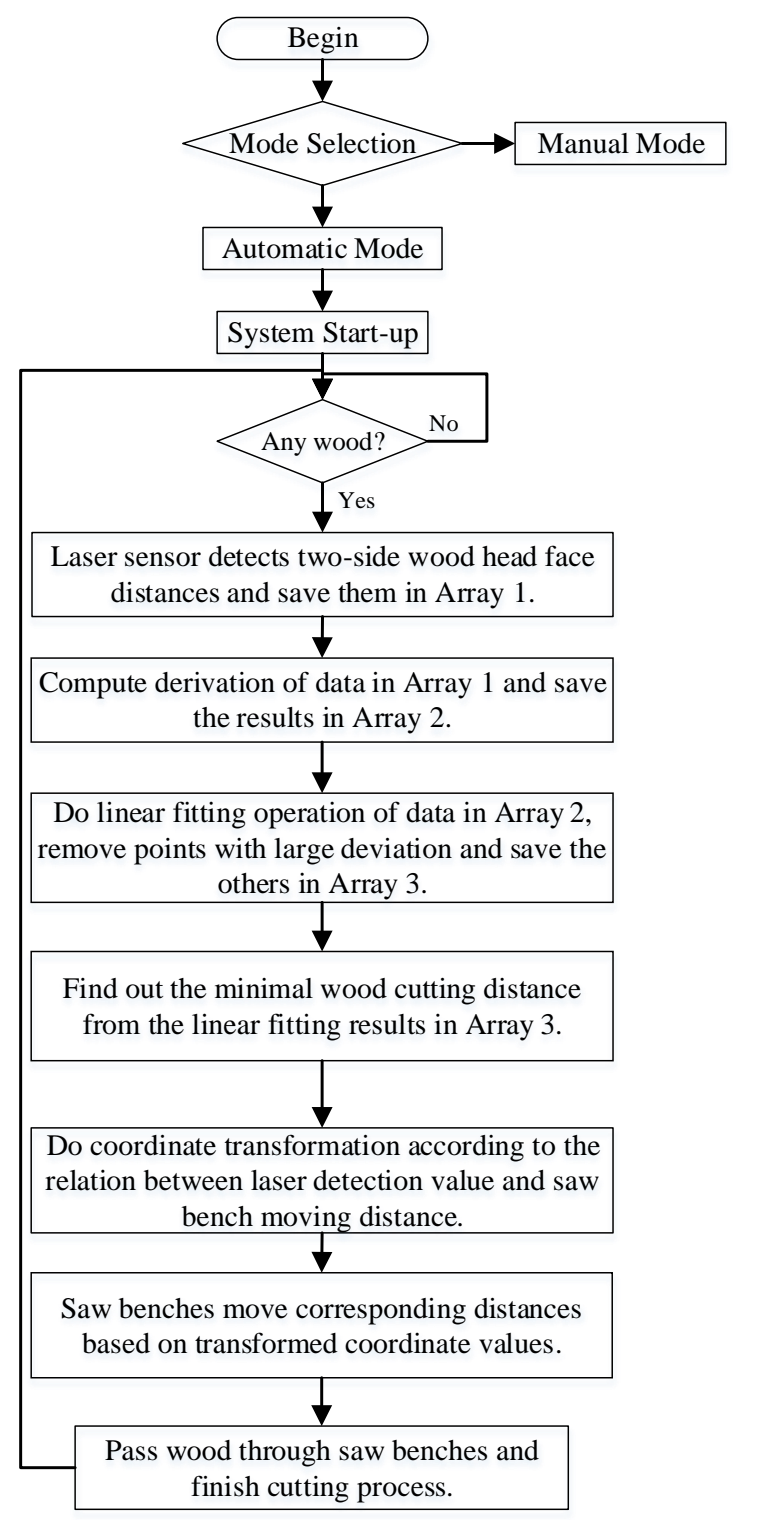

Figure 3: Control Flow of Full-automatic Double-ended Trim Saw

\subsection{Touch Screen Design}

HMI adopts Delta touch screen which owns large market share and achieves switch of operation modes as well as parameter settings of sensors [9]. Current states of devices such as photoelectric switch, limit switch and servo motor can also be monitored by this type of touch screen. The device operation interface is depicted in Figure 4, and the servo motor parameter settings and status display are shown in Figure 5. 


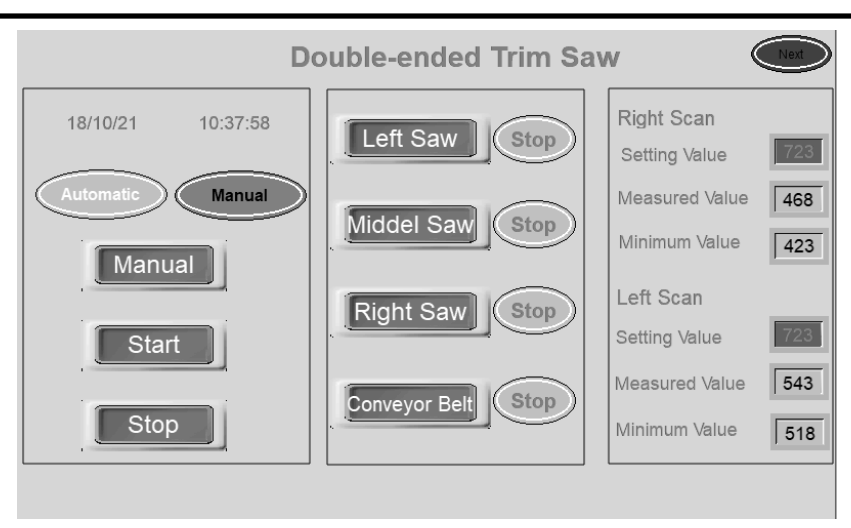

Figure 4: Operation Interface of Full-automatic Double-ended Trim Saw

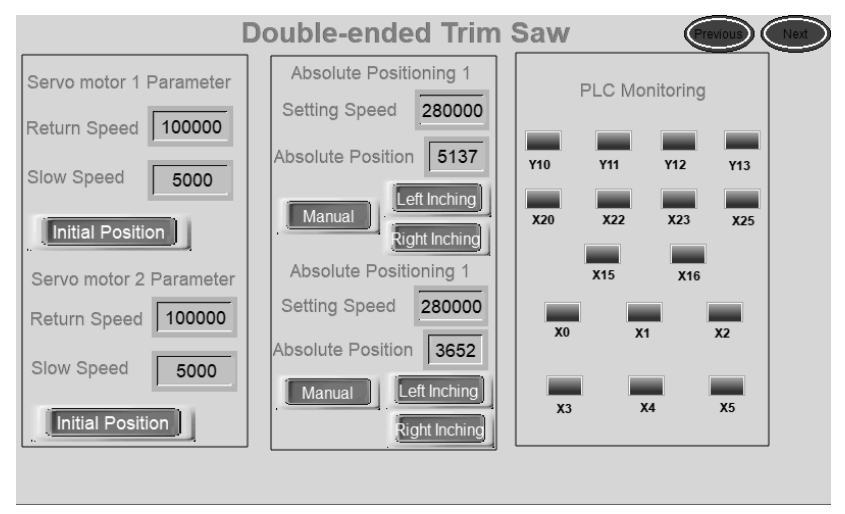

Figure 5: Servo Motor Parameter Settings and Status Display of Trim Saw

\subsection{System Security Design}

To keep personal and device safety during the production process, fault alarm program has been designed for the trim saw system. When an error occurs in the process of wood processing, the alarm program will be triggered, and the device will automatically stop. Moreover, there are also emergency stop buttons in both feeding and cutting units. In case of any emergency situations, the operator can stop the devices in urgency by pressing either of the two buttons.

\section{APPLICATION EFFECT ANALYSIS}

Our designed full-automatic double-ended trim saw has been successfully applied in production of certain wood processing factory in Jilin City. By applying the automatic trim saw in this factory, we obtain ten groups of double-ended wood trim processing test data with different length which are shown in Table 1.

Among the ten groups of wood processing test data, the maximum absolute error and relative error of A-end are $0.8 \mathrm{~cm}$ and $1.06 \%$ respectively, while these two terms of $\mathrm{B}$-end are $1 \mathrm{~cm}$ and $1.36 \%$ separately. According to the technological requirements of double-ended wood trim process, the maximum tolerance range should be $\pm 1 \mathrm{~cm}$. Hence, we can conclude from the test data that our designed fullautomatic double-ended trim saw completely satisfies the precision requirement of wood processing.

Table 1: Ten Groups of Wood Processing Test Data with Different Length

\begin{tabular}{|c|c|c|c|c|c|c|c|}
\hline $\begin{array}{l}\text { Test } \\
\text { Material }\end{array}$ & $\begin{array}{l}\text { Wood } \\
\text { Length }\end{array}$ & $\begin{array}{l}\text { A-end Ideal } \\
\text { Cutting Distance }\end{array}$ & $\begin{array}{l}\text { A-end Actual } \\
\text { cutting distance }\end{array}$ & $\begin{array}{l}\text { A-end } \\
\text { Relative } \\
\text { Error* }\end{array}$ & $\begin{array}{l}\text { B-end Ideal } \\
\text { Cutting Distance }\end{array}$ & $\begin{array}{l}\text { B-end Actual } \\
\text { Cutting Distance }\end{array}$ & $\begin{array}{l}\text { B-end } \\
\text { Relative } \\
\text { Error* }\end{array}$ \\
\hline Wood 1 & $66 \mathrm{~cm}$ & $3.5 \mathrm{~cm}$ & $4.2 \mathrm{~cm}$ & $1.06 \%$ & $4.3 \mathrm{~cm}$ & $5.2 \mathrm{~cm}$ & $1.36 \%$ \\
\hline Wood 2 & $73 \mathrm{~cm}$ & $4.3 \mathrm{~cm}$ & $4.8 \mathrm{~cm}$ & $0.68 \%$ & $1.8 \mathrm{~cm}$ & $2.5 \mathrm{~cm}$ & $0.95 \%$ \\
\hline Wood 3 & $79 \mathrm{~cm}$ & $2.8 \mathrm{~cm}$ & $2.6 \mathrm{~cm}$ & $0.25 \%$ & $3.4 \mathrm{~cm}$ & $3.1 \mathrm{~cm}$ & $0.37 \%$ \\
\hline Wood 4 & $86 \mathrm{~cm}$ & $3.1 \mathrm{~cm}$ & $3.9 \mathrm{~cm}$ & $0.93 \%$ & $5.1 \mathrm{~cm}$ & $4.6 \mathrm{~cm}$ & $0.58 \%$ \\
\hline Wood 5 & $93 \mathrm{~cm}$ & $2.3 \mathrm{~cm}$ & $1.8 \mathrm{~cm}$ & $0.53 \%$ & $4.7 \mathrm{~cm}$ & $5.3 \mathrm{~cm}$ & $0.64 \%$ \\
\hline Wood 6 & $97 \mathrm{~cm}$ & $1 \mathrm{~cm}$ & $1.6 \mathrm{~cm}$ & $0.61 \%$ & $3.2 \mathrm{~cm}$ & $4.2 \mathrm{~cm}$ & $1.03 \%$ \\
\hline Wood 7 & $102 \mathrm{~cm}$ & $4.7 \mathrm{~cm}$ & $5.5 \mathrm{~cm}$ & $0.78 \%$ & $2.4 \mathrm{~cm}$ & $2.2 \mathrm{~cm}$ & $0.19 \%$ \\
\hline Wood 8 & $107 \mathrm{~cm}$ & $2.6 \mathrm{~cm}$ & $2.4 \mathrm{~cm}$ & $0.18 \%$ & $3.7 \mathrm{~cm}$ & $4.4 \mathrm{~cm}$ & $0.65 \%$ \\
\hline Wood 9 & $114 \mathrm{~cm}$ & $1.8 \mathrm{~cm}$ & $2.4 \mathrm{~cm}$ & $0.52 \%$ & $4.2 \mathrm{~cm}$ & $3.9 \mathrm{~cm}$ & $0.26 \%$ \\
\hline Wood 10 & $118 \mathrm{~cm}$ & $5.2 \mathrm{~cm}$ & $5.9 \mathrm{~cm}$ & $0.59 \%$ & $2.5 \mathrm{~cm}$ & $3.2 \mathrm{~cm}$ & $0.59 \%$ \\
\hline
\end{tabular}

Notes. Relative Error $=\frac{\text { Actual Cutting Distance }- \text { Ideal Cutting Distance }}{\text { Wood Length }} * 100 \%$.

\section{CONCLUSION}

The full-automatic double-ended trim saw designed in this paper improves the automaticity of wood processing device as well as effectively guarantees both personal safety and device security in the process of the wood processing. Furthermore, by applications in practical production, our designed trim saw is verified to meet the technological requirements of wood processing in both processing precision and system performance. In conclusion, our designed automatic trim saw system has advantages in reducing production cost as well as raising both the enterprise productivity and profit and owns considerable market prospect.

\section{REFERENCES}

[1] Yang, H., Ren, Z. 2009. Brief discussions on wood processing machinery in China. Heilongiiang Science and Technology Information, 25, 136-136. doi: 10.3969/j.issn.1673-1328.2009.25.137
[2] Ding, J., Wang, B., Xu, Z. 2005. Photoelectricity scanning technology using in wood industry. Wood Processing Machinery, 16 (1), 32-35. doi: 10.3969/j.issn.1001-036X.2005.01.010

[3] Wu, C., Tang, Q., Zhang, S., Zhang, C. 2010. Study on intelligence and energy-saving control of wood sub-saw. Electric Age, 29 (11), 72-74.

[4] Li, R., Cao, P., Zhou, Z. 2013. Design of two-side circular saw for slabbing small-diameter logs. China Forestry Science and Technology, 27 (6), 112-114. doi: 10.3969/j.issn.1000-8101.2013.06.029

[5] Zhang, J., Yao, X., Song, K. 2006. Mixture processes and optimizing cross-cutting saw of solid wood furniture. International Wood Industry, 36 (5), 24-26.

[6] Wang, X. 2011. Resolve of PLC control system design method. Automation \& Instrumentation, 1, 43-44+48. doi: 10.3969/ j.issn.1001-9227.2011.01.017 
[7] Gao, Q. 2006. Application technology and design examples of programmable controller. Beijing, China: Posts \& Telecom Press

[8] Yang, G. 2004. Principle and application of programmable controller (PLC). Beijing, China: Publishing House of Electronics Industry.

[9] Ji, L. 2006. Study on supervisory control configuration software and its database. Unpublished master thesis, Wuhan University of Technology, Wuhan, China. doi: 10.7666/d.y861007

\section{ABOUT THE AUTHORS}

Sun Mingge (1971-): Male, Yushu City, Jilin Province, received doctor degree from Jilin University in 2010, professor of Jilin Institute of Chemical Technology, mainly researching on industrial automatic control and machine vision.

Zhang Jie (1986-): Male, Gaomi City, Shandong Province, postgraduate of Jilin Institute of Chemical Technology, mainly researching on industrial automatic control.

Zhang Xiaodong (1965-): Female, Siping City, Jilin Province, received master degree from Dalian University of Technology in 2005, associate professor of Jilin Institute of Chemical Technology, mainly researching on pattern recognition and image processing. 